\title{
Association Between Chronic Kidney Disease Progression and Cardiovascular Disease: Results from the CRIC Study
}

\author{
Mahboob Rahman ${ }^{a}$ Dawei Xie ${ }^{b}$ Harold I. Feldman ${ }^{b}$ Alan S. Go ${ }^{c}$ Jiang He ${ }^{d}$ \\ John W. Kusek ${ }^{\mathrm{e}}$ James Lash $^{f}$ Edgar R. Miller III9 Akinlolu Ojo $^{\mathrm{h}}$ Qiang Pan $^{\mathrm{b}}$ \\ Stephen L. Seliger ${ }^{i}$ Susan Steigerwalt ${ }^{j} \quad$ Ray R. Townsend $^{b}$ for the CRIC Study \\ Investigators
}

${ }^{a}$ Case Western Reserve University, University Hospitals Case Medical Center, Louis Stokes Cleveland VA Medical Center, Cleveland, Ohio, b University of Pennsylvania, Philadelphia, Pa., 'Kaiser Permanente of Northern California, Oakland, Calif., d Tulane University, New Orleans, La., e National Institute of Diabetes and Digestive and Kidney Diseases, Bethesda, Md., f University of Illinois, Chicago, Ill., g Johns Hopkins University, Baltimore, Md., h University of Michigan, Ann Arbor, Mich., and 'University of Maryland School of Medicine, Baltimore, Md. and ${ }^{j}$ Renaissance Renal Research Institute, St. John's Hospital, Detroit, Mich., USA

\section{Key Words}

Self-reported CVD · Progression of CKD · Heart failure

\begin{abstract}
Background and Aims: There is limited information on the risk of progression of chronic kidney disease (CKD) among individuals with CVD (cardiovascular disease). We studied the association between prevalent CVD and the risk of progression of CKD among persons enrolled in a long-term observational study. Methods: A prospective cohort study of 3,939 women and men with CKD enrolled in the chronic renal insufficiency cohort (CRIC) study between June 2003 and June 2008. Prevalent cardiovascular disease (myocardial infarction/revascularization, heart failure, stroke, and peripheral vascular disease) was determined by self-report at baseline. The primary outcome was a composite of either endstage renal disease or a $50 \%$ decline in estimated glomerular
\end{abstract}

filtration rate (eGFR) from baseline. Results: One-third (1,316 of $3,939,33.4 \%$ ) of the study participants reported a history of any cardiovascular disease, and $9.6 \%(n=382)$ a history of heart failure at baseline. After a median follow up of 6.63 years, 1,028 patients experienced the primary outcome. The composite of any CVD at baseline was not independently associated with the primary outcome (Hazard Ratio $1.0495 \%$ $\mathrm{Cl}(0.91,1.19))$. However, a history of heart failure was independently associated with a $29 \%$ higher risk of the primary outcome (Hazard Ratio $1.2995 \% \mathrm{Cl}(1.06,1.57)$ ). The relationship between heart failure and risk of CKD progression was consistent in subgroups defined by age, race, gender, baseline eGFR, and diabetes. Neither the composite measure of any CVD or heart failure was associated with the rate of decline in eGFR. Conclusions: Self-reported heart failure was an independent risk factor for the development of the endpoint of ESRD or $50 \%$ decline in GFR in a cohort of patients with chronic kidney disease.

(c) 2014 S. Karger AG, Basel

\section{KARGER}

E-Mail karger@karger.com www.karger.com/ajn
(2) 2014 S. Karger AG Basel

0250-8095/14/0405-0399\$39.50/0
Mahboob Rahman, MD

11100 Euclid Ave

Cleveland, OH 44106 (USA)

E-Mail Mahboob.Rahman@uhhospitals.org 


\section{Introduction}

Cardiovascular disease (CVD) significantly increases the risk for morbidity and mortality in patients with chronic kidney disease (CKD). Conversely, persons with CKD are at increased risk for CVD [1]. However, the impact of CVD among persons with established CKD on progression of their kidney disease is uncertain [2]. Possible reasons why patients with both CVD and CKD may be at a higher risk for progression of kidney disease include shared risk factors (such as diabetes, hypertension, hyperlipidemia, smoking, etc.) [3, 4], atherosclerosis affecting the renal vasculature [5], homeostatic changes that decrease renal perfusion in the setting of heart failure [6], and exposure to contrast dye and atheroemboli from diagnostic procedures. Improved understanding of the association between prevalent cardiovascular disease and progression of CKD may not only enhance the prognosis for kidney disease, but also lead to future studies of the pathophysiology of these two commonly coexistent diseases.

The chronic renal insufficiency cohort (CRIC) study is an ongoing, multicenter, prospective observational study of men and women with CKD established to study the risk factors for the progression of $\mathrm{CKD}$, including $\mathrm{CVD}$ [7]. We studied self-reported cardiovascular disease, overall and in subtypes of CVD, among the CRIC Study participants at the time of enrollment (baseline) and its association with the rate of $\mathrm{CKD}$ progression during follow-up.

\section{Materials and Methods}

The design and methods of the CRIC Study, and baseline characteristics of the participants have been published in detail previously $[7,8]$. Briefly, the CRIC Study enrolled men and women with mild-to-moderate CKD (approximately one-half who reported having diabetes and about one-half African American) at seven clinical centers. Persons aged 21-44 years were eligible for the study if their estimated GFR (eGFR) was between 20 and $70 \mathrm{ml} /$ $\mathrm{min} / 1.73 \mathrm{~m}^{2}$, while those between $45-64$ years and $65-74$ years, had to have an eGFR between 20 and $60 \mathrm{ml} / \mathrm{min} / 1.73 \mathrm{~m}^{2}$, and 20 and $50 \mathrm{ml} / \mathrm{min} / 1.73 \mathrm{~m}^{2}$, respectively. Persons with additional primary renal diseases requiring active immunosuppression within six months of enrollment, polycystic kidney disease, significant coexisting illnesses (including New York Heart Association class III or IV chronic heart failure, cirrhosis, HIV infection/AIDS), systemic cancer requiring chemotherapy, and those with prior organ or bone marrow transplantation were excluded. A total of 3,939 subjects completed a baseline visit and were enrolled from May 2003 to June 2008. The institutional review boards at all participating institutions approved the study protocol and the research was conducted in accordance with the ethical principles of the Declaration of Helsinki. Written informed consent was obtained from all study participants.

Demographic characteristics, medical history, and lifestyle factors were provided by the study participants; medication use within the previous 30 days was determined from prescription drugs brought to the clinic. Blood pressure, height, weight, and anklebrachial index were measured using standardized procedures. Hypertension was defined as either systolic blood pressure $\geq 140 \mathrm{~mm}$ $\mathrm{Hg}$, or diastolic blood pressure $\geq 90 \mathrm{~mm} \mathrm{Hg}$, or use of antihypertensive medications. Diabetes was defined as either a fasting glucose $\geq 126 \mathrm{mg} / \mathrm{dl}$, or a random glucose $\geq 200 \mathrm{mg} / \mathrm{dl}$, or use of insulin or oral anti-diabetic medications. EGFR was calculated using an equation derived from CRIC study participants using serum creatinine and cystatin C levels, age, sex, and race [9].

CVD at baseline was determined by participants self-report. Participants were asked:

- 'Have you ever been diagnosed with or has a doctor or other health professional ever told you that you have

- coronary artery disease (heart attack, angina)

- prior revascularization of your heart blood vessels (e.g., balloon angioplasty, coronary stenting, coronary bypass surgery)

- heart failure

- stroke or

- peripheral vascular disease (claudication, amputation, or procedure to open up blood vessels in the arms or legs)'.

The composite measure of 'any' prevalent CVD was defined as a positive answer to any of the types of CVD described above. The primary outcome was CKD progression defined as either an occurrence of ESRD (initiation of maintenance dialysis or kidney transplantation) or a $50 \%$ decline in eGFR from baseline. The rate of change of eGFR was also evaluated using the serum creatinine measurement obtained annually.

\section{Statistical Analyses}

Descriptive statistics were used to compare the clinical characteristics according to baseline history of any CVD (composite) and each type of CVD (data shown only for heart failure); Chi-square and ANOVA tests were used for categorical and continuous variables, respectively. Cox regression models were used to examine the association between the baseline history of any CVD and the outcome. Covariates were selected a priori on the basis of previously described risk factors for CKD progression. We first modeled any CVD, then the history of myocardial infarction (MI)/prior revascularization, congestive heart failure, stroke, and peripheral vascular disease (PVD) separately. We used a tiered approach to study the association between baseline CVD and the primary outcome. First, the relationship between the baseline history of any CVD and the primary outcome was evaluated in univariate analyses. Demographic characteristics (age, gender, and race) and the clinical center where participants were recruited were added to Model 2 to account for possible differences based on the geographic location of the participant. Systolic blood pressure, triglycerides, HDL, body mass index, smoking, diabetes, eGFR, $24 \mathrm{~h}$ urine protein, angiotensin converting enzyme/angiotensin receptor blocker use, and hemoglobin were added to Model 3. Fibroblast growth factor (FGF)23 was added as an additional covariate in sensitivity analyses. The unadjusted relationships between the history of any CVD and individual components of CVD (only composite and heart failure are shown) and the primary outcomes are depicted in Kaplan Meier 
curves with log rank testing for statistical significance of the difference between groups. To explore whether there was effect modification, we repeated the models on the history of CHF in subgroups defined at baseline by age, sex, race/ethnicity, diabetes status, level of eGFR, and level of $24 \mathrm{~h}$ urine protein excretion, and tested for interaction by subgroup. In all models that included $24 \mathrm{~h}$ urine protein excretion and eGFR, the two strongest predictors for CKD progression, we explored the nonlinear terms and relaxed the linearity assumptions for urine protein using quadratic splines (with one knot at the median) of natural log-transformed $24 \mathrm{~h}$ urine protein [10]. We did not find sufficient evidence to support a nonlinear relationship between eGFR and the renal outcome. The proportional hazards assumption was met based on cumulative Martingale residuals [11]. In the Cox regression models, participants were censored either at the time of death, withdrawal from the study, or their last study visit (for those who did not withdraw, but did not come for regular visits) or on March 31, 2012, whichever occurred first. Hazard ratios and their 95\% confidence intervals (CI) were reported. Models including death as a competing risk using the Fine and Gray method were also performed [12]. Since the aim of our study was to look for etiologic association, we used Cox regression as our primary analyses, and competing risk models as sensitivity analyses [13]. In the analyses of rate of change of GFR, we estimated the associations between baseline CVD with the slope of eGFR decline over the follow-up period using the linear mixed effects models with both random intercept and slope terms. Parameter estimates were reported as the slope difference between participants with and without baseline CVD. In the multivariable adjusted model, we adjusted for the same covariates as were in the survival analysis. All data analyses were conducted using SAS version 9.3 (SAS Institute, Cary, N.C., USA). All statistical tests were double-sided, and $\mathrm{p}<$ 0.05 were considered statistically significant.

\section{Results}

One-third (33.4\%) of study participants reported a history of any cardiovascular disease at baseline (table 1). Participants with a history of CVD were more likely to be older, male, black, current smokers, hypertensive, have diabetes, higher systolic and diastolic blood pressures, $\mathrm{BMI}$, fasting glucose and urinary protein excretion, and lower eGFR than participants without a history of CVD. Self-reported any CVD was more prevalent among persons with a lower eGFR compared to a higher eGFR (fig. 1) overall and for each type of CVD. Participants with self-reported heart failure $(n=382,9.6 \%)$ had higher levels of BNP and NT pro-BNP at baseline than participants who did not report a history of heart failure (online suppl. table 1; for all online suppl. material, see www. karger.com/doi/10.1159/000368915).

After a median follow up of 6.63 years, 1,028 participants experienced the primary outcome. Unadjusted event rates for the primary outcome were higher in those with a history of cardiovascular disease compared to those without, (77.1 and 54.0 per 1,000 person years, respectively), and higher in persons who reported a history of heart failure compared to those without a history of heart failure (97.0 and 58.1 per 1,000 person years, respectively) (fig. 2).

In unadjusted models, the composite measure of any CVD at baseline was associated with a higher risk of the primary outcome (HR 1.44, 95\% CI 1.27, 1.62); but the association became nonsignificant after adjustment for covariates (listed in table 2) (HR 1.04 95\% CI $(0.91,1.19)$ ). Participants with a history of $\mathrm{MI} /$ revascularization, stroke or, peripheral arterial disease were also more likely to develop a primary outcome in unadjusted analyses but this risk was also attenuated and of borderline significance for $\mathrm{MI} /$ revascularization and not significant for stroke or peripheral arterial disease after adjustment for other covariates (table 2). In contrast, a history of congestive heart failure was associated with a $29 \%$ higher risk of the primary outcome (HR 1.29 95\% CI 1.06, 1.57) after adjustment for other risk factors for CKD progression (table 2). The increased risk was similar in sub-groups defined by age, race, gender, diabetes, eGFR, and proteinuria (fig. 3). The association between heart failure and the primary outcome was consistent in sensitivity analysis when further adjusted for inflammatory markers (IL-6 and C-reactive protein log transformed) HR 1.28* (CI 1.05, 1.56). In analyses where death was considered a competing risk, heart failure was associated with the primary outcome in unadjusted, but not in fully adjusted models (online suppl. table 2).

The overall mean annual rate of decline in eGFR was $-1.85 \mathrm{ml} / \mathrm{min} / 1.73 \mathrm{~m}^{2}$. The association between prevalent CVD and the rate or change of GFR is presented in table 3. In unadjusted analyses, the presence of any CVD was associated with a faster decline in eGFR; however, in adjusted models, neither any CVD nor subtypes of CVD were significantly associated with rate of decline in eGFR.

Results were consistent for the primary outcome and the rate of change of GFR in models adjusted for FGF-23 in addition to the variables mentioned above in model 3 . (online suppl. table 3).

\section{Discussion}

Among a large cohort of men and women with mildto-moderate $\mathrm{CKD}$, including many African Americans and persons with diabetes, self-report of any CVD was highly prevalent at baseline. Although the presence of any CVD was associated with higher rates of progression of 
Table 1. Baseline characteristics of study population, overall and stratified by any CVD n (\%) or mean (SD)

\begin{tabular}{|c|c|c|c|c|c|}
\hline & & $\begin{array}{l}\text { Overall } \\
\mathrm{n}=3,939\end{array}$ & $\begin{array}{l}\text { Any self-reported } \\
\text { CVD at baseline } \\
n=1,316\end{array}$ & $\begin{array}{l}\text { No CVD reported } \\
\text { at baseline } \\
n=2,623\end{array}$ & $\mathrm{p}$ value \\
\hline \multirow{2}{*}{ Age, years } & 45 to $<65$ & $2,261(57.4)$ & $772(58.7)$ & $1,489(56.8)$ & $<0.0001$ \\
\hline & $65+$ & $1,140(28.9)$ & $504(38.3)$ & $636(24.2)$ & $<0.0001$ \\
\hline \multirow[t]{4}{*}{ Race-ethnicity } & non-Hispanic white & $1,638(41.6)$ & $507(38.5)$ & $1,131(43.1)$ & $<0.0001$ \\
\hline & non-Hispanic black & $1,650(41.9)$ & $627(47.6)$ & $1,023(39.0)$ & $<0.0001$ \\
\hline & Hispanic & 497 (12.6) & $138(10.5)$ & $359(13.7)$ & $<0.0001$ \\
\hline & other & $154(3.9)$ & $44(3.3)$ & $110(4.2)$ & $<0.0001$ \\
\hline Current smoker & & $517(13.1)$ & $202(15.3)$ & $315(12.0)$ & 0.003 \\
\hline Hypertension & & $3,391(86.1)$ & $1,212(92.1)$ & $2,179(83.1)$ & $<0.0001$ \\
\hline Diabetes & & $1,908(48.4)$ & $816(62.0)$ & $1,092(41.6)$ & $<0.0001$ \\
\hline \multirow[t]{3}{*}{ Body mass index category } & $<25$ & $630(16.0)$ & $170(13.0)$ & $460(17.6)$ & 0.0002 \\
\hline & 25 to $<30$ & $1,125(28.6)$ & $364(27.8)$ & $761(29.0)$ & 0.0002 \\
\hline & $>30$ & $2,174(55.3)$ & $775(59.2)$ & $1,399(53.4)$ & 0.0002 \\
\hline \multirow[t]{4}{*}{ Ankle brachial index } & $<0.90$ & $625(16.1)$ & $362(28.3)$ & $263(10.1)$ & $<0.0001$ \\
\hline & $0.90-<1.10$ & $1,813(46.8)$ & $547(42.7)$ & $1,266(48.7)$ & $<0.0001$ \\
\hline & $1.10-<1.40$ & $1,343(34.6)$ & $331(25.9)$ & $1,012(39.0)$ & $<0.0001$ \\
\hline & $>1.40$ & $96(2.5)$ & $40(3.1)$ & $56(2.2)$ & $<0.0001$ \\
\hline $24 \mathrm{~h}$ urine protein, $\mathrm{g} / 24 \mathrm{~h}$ & $\begin{array}{l}\text { median } \\
\text { (interquartile range) }\end{array}$ & $0.18(0.07-0.91)$ & $0.25(0.08-1.15)$ & $0.16(0.07-0.81)$ & $<0.0001$ \\
\hline Hemoglobin, g/dl & & $12.60(1.78)$ & $12.37(1.75)$ & $12.72(1.77)$ & $<0.0001$ \\
\hline Calcium, mg/dl & & $9.18(0.51)$ & $9.17(0.51)$ & $9.18(0.51)$ & 0.56 \\
\hline Phosphate, mg/dl & & $3.73(0.67)$ & $3.79(0.71)$ & $3.70(0.65)$ & $<0.0001$ \\
\hline $\begin{array}{l}\text { Fibroblast growth factor-23, } \\
\text { FGF-23, RU/ml }\end{array}$ & & $233.28(462.71)$ & $281.93(457.49)$ & $208.81(463.47)$ & $<0.0001$ \\
\hline Total parathyroid hormone, $\mathrm{pg} / \mathrm{ml}$ & & $75.01(71.35)$ & $84.91(82.01)$ & $70.10(64.87)$ & $<0.0001$ \\
\hline Brain natriuretic peptide (BNP) & & $102.61(256.77)$ & $172.99(319.33)$ & $67.79(210.87)$ & $<0.0001$ \\
\hline $\begin{array}{l}\text { N-terminal pro b-type natriuretic } \\
\text { peptide, pg/ml }\end{array}$ & & $568.16(1,868.6)$ & $1,005.2(2,476.4)$ & $350.41(1,426.4)$ & $<0.0001$ \\
\hline
\end{tabular}


Fig. 1. Prevalence of self-reported CVD in CRIC participants stratified by baseline $\operatorname{eGFR}\left(\mathrm{ml} / \mathrm{min} / 1.73 \mathrm{~m}^{2}\right)$.
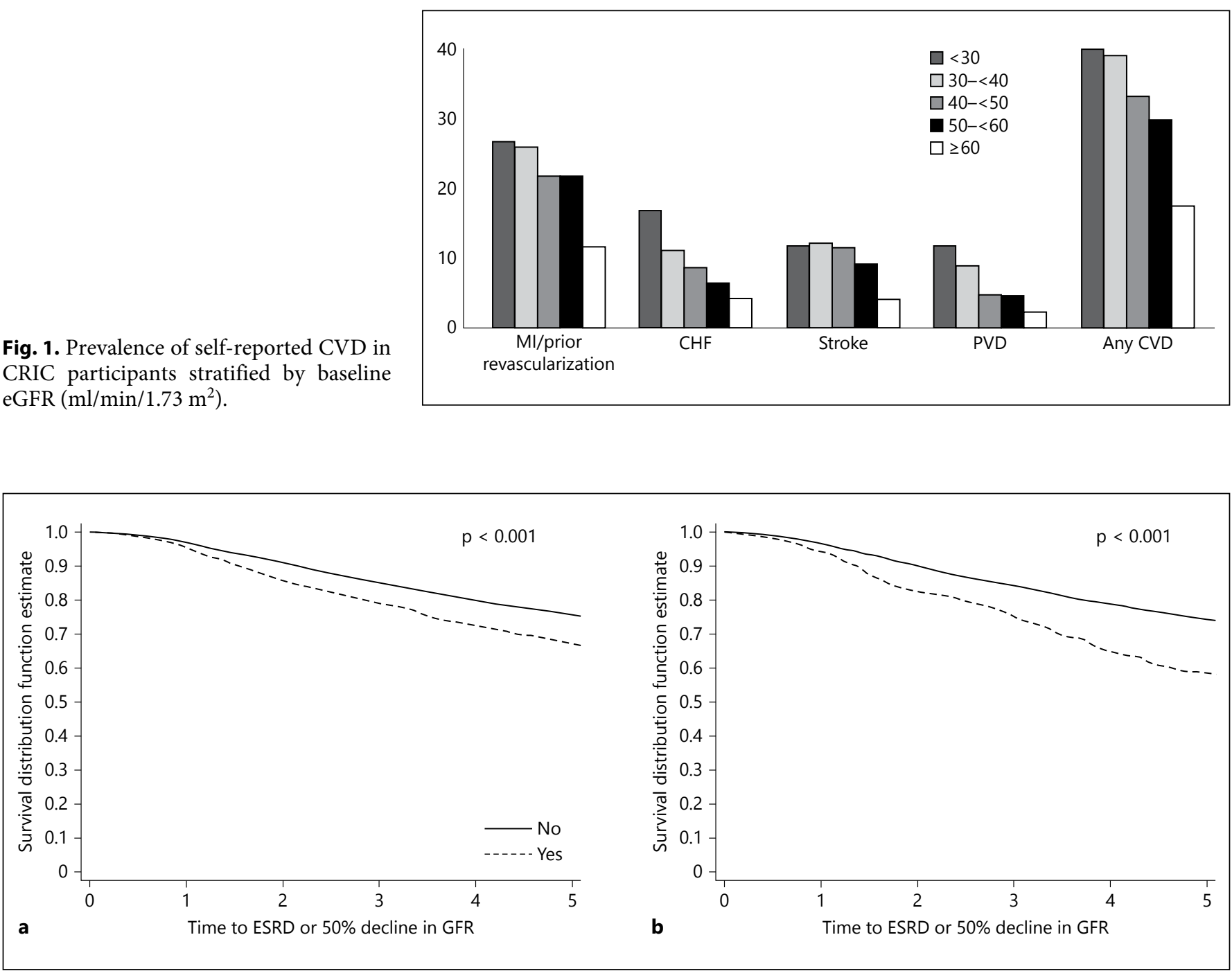

Fig. 2. a, b Kaplan Meir plots of ESRD or 50\% decline in eGFR by history of any CVD (a) and heart failure (b) at baseline (unadjusted).

Table 2. Association of any CVD and subtypes of CVD with ESRD or 50\% decline in eGFR from baseline

\begin{tabular}{|c|c|c|c|c|c|}
\hline Model & \multicolumn{5}{|c|}{ Hazard ratio (95\% CI) for ESRD/eGFR 50\% decline } \\
\hline $\begin{array}{l}\text { Model 2: Model } 1+\text { gender, age, race, } \\
\text { and clinical sites }\end{array}$ & $1.41^{*}(1.24,1.61)$ & $1.26^{*}(1.09,1.46)$ & $1.48^{*}(1.22,1.79)$ & $1.07(0.88,1.30)$ & $1.81^{*}(1.48,2.22)$ \\
\hline
\end{tabular}

${ }^{*} \mathrm{p}<0.05 . \mathrm{HDL}=$ High density lipoprotein; $\mathrm{eGFR}=$ estimated glomerular filtration rate; $\mathrm{ACE}=$ angiotensin converting enzyme inhibitor; $\mathrm{ARB}=$ angiotensin receptor blocker. 
Fig. 3. Legend Hazard ratios of risk of ESRD or $50 \%$ decline in kidney function in patients with heart failure in subgroups based on sex, age, race, and clinical sites (Adjusted for systolic blood pressure, triglycerides, HDL, body mass index, smoking, diabetes, eGFR, urine protein, ACE/ ARB use hemoglobin, FGF-23).

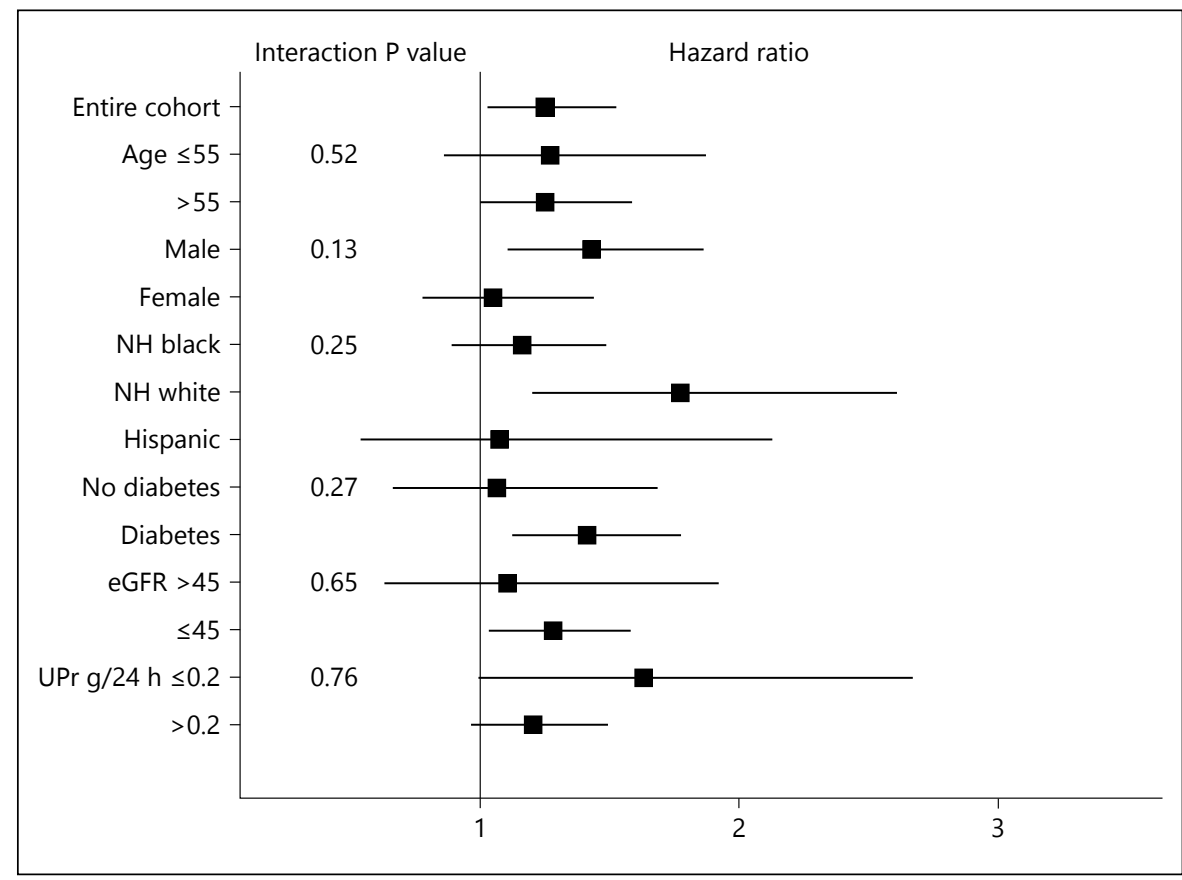

Table 3. Association of any CVD and subtypes of CVD rate of change of GFR over time

\begin{tabular}{|c|c|c|c|c|c|}
\hline \multirow[t]{2}{*}{ Model } & \multicolumn{5}{|c|}{$\begin{array}{l}\text { Rate of change of GFR } \\
\text { slope parameter estimate }\left(\mathrm{ml} / \mathrm{min} / 1.73 \mathrm{~m}^{2} / \text { year}\right) \text { (standard error) }\end{array}$} \\
\hline & any CVD & $\begin{array}{l}\mathrm{MI} / \text { prior } \\
\text { revascularization }\end{array}$ & heart failure & stroke & $\begin{array}{l}\text { peripheral vascular } \\
\text { disease }\end{array}$ \\
\hline Model 1: unadjusted & $-0.40(0.09)^{*}$ & $-0.32(0.1)^{*}$ & $-0.44(0.16)^{*}$ & $-0.24(0.15)$ & $-0.64(0.19)^{*}$ \\
\hline $\begin{array}{l}\text { Model 2: Model } 1+\text { gender } \\
\text { age, race, and clinical sites }\end{array}$ & $-0.35(0.1)^{*}$ & $-0.32(0.11)^{*}$ & $-0.27(0.16)$ & $-0.07(0.15)$ & $-0.57(0.19)^{*}$ \\
\hline $\begin{array}{l}\text { Model 3: Model } 2+\text { systolic BP, } \\
\text { triglycerides, HDL, body mass } \\
\text { index, smoking, diabetes, eGFR, urine } \\
\text { protein, ACE/ARB use hemoglobin }\end{array}$ & $-0.07(0.09)$ & $-0.16(0.1)$ & $-0.10(0.15)$ & $-0.02(0.13)$ & $0.08(0.17)$ \\
\hline
\end{tabular}

$* \mathrm{p}<0.05 . \mathrm{HDL}=$ High density lipoprotein; EGFR = estimated glomerular filtration rate; ACE = angiotensin converting enzyme inhibitor; $\mathrm{ARB}=$ angiotensin receptor blocker.

$\mathrm{CKD}$, the increased risk was not observed after adjustment for common risk factors for CKD progression. This suggests that the high prevalence of risk factors for vascular disease, rather than the cardiovascular disease per se, accounts for the high rates of CKD progression in persons with CVD. In contrast, self-reported history of heart failure remained a robust and independent predictor of the primary outcome after adjustment of level of kidney function (eGFR) and proteinuria, the two strongest risk factors for decline in kidney function in our cohort. However, there was no association between baseline heart failure and the rate of change of eGFR.

The substantial burden of cardiovascular disease reported by the CRIC study participants at enrollment was anticipated [1]. Long-term follow-up of this cohort provided the opportunity to determine whether the presence of cardiovascular disease was associated with the rate of progression of CKD. Few studies of persons with estab- 
lished CKD have reported the risk of CKD progression related to coexisting CVD. In a small cohort of 313 patients (predominantly men) with a mean creatinine clearance of $36 \mathrm{ml} / \mathrm{min}$, the presence of CVD conferred an increased risk for progression to ESRD (relative risk $[\mathrm{RR}]=1.58, \mathrm{p}=$ 0.047 ) [14]. Several large, community-based studies in persons with better preserved kidney function have shown that cardiovascular disease also increased the risk of progression of CKD [15]. Among the Cardiovascular Health Study (CHS) participants whose mean eGFR was $80 \mathrm{ml} /$ $\mathrm{min} / 1.73 \mathrm{~m}^{2}$ at baseline, prevalent stroke (OR, 95\% CI: $1.55,1.16-2.08$ ) and heart failure (OR, 95\% CI: 1.80, 1.402.31) were both independent predictors of the rapid decline of kidney function (eGFR loss $>3 \mathrm{ml} / \mathrm{min} / 1.73 \mathrm{~m}^{2}$ per year) [16]. In combined analyses of the Atherosclerosis Risk in Communities Study and CHS, participants (baseline mean eGFR of $89.8 \mathrm{ml} / \mathrm{min} / 1.73 \mathrm{~m}^{2}$ ) with CVD at baseline (defined by stroke, angina, claudication, transient ischemic attack, coronary angioplasty or bypass, and recognized or silent myocardial infarction) were more likely to experience kidney function decline and the development of kidney disease [17]. However, the association between heart failure and progression of CKD was not reported.

The relationship between cardiac and kidney function has generated considerable interest in the last few years, resulting in a formal classification of cardiorenal syndromes $[18,19]$. Most attention was given to an acute decline in kidney and cardiac function in decompensated states. Under the paradigm of type 2 cardiorenal syndrome, heart failure contributes to the decline in kidney function over time; however, there are only a few reports that have studied this relationship [18, 20]. While several cross-sectional studies have reported the high prevalence of chronic kidney disease in patients with heart failure $[21,22]$, the temporal relationship of these two diseases is not clear. Similarly, there is little information about the incidence and persistence of renal dysfunction in patients with chronic heart failure in the outpatient setting [23]. Our study showed that ambulatory CKD patients with self-reported heart failure are more likely to have significant declines in GFR or reach ESRD over time. It is important to note that these findings apply to the earlier stages of heart failure, since the presence of New York Heart Association class III and IV heart failure was an exclusion criterion for the CRIC study.

The pathophysiology of the relationship between cardiac and kidney function is complex. In the setting of hospitalized acute decompensated heart failure, decline in kidney function has been well described, and thought to relate to decreased renal perfusion from low cardiac out-

CVD as a Risk Factor for CKD

Progression put, volume depletion from excessive diuretic therapy, and more recently to venous congestion [24, 25]. It is hypothesized that lower cardiac output and a decreased effective circulating blood volume result in baroreceptor stimulation, increased sympathetic nervous activity, and renin secretion with increased sodium reabsorption and constriction of glomerular mesangial cells decreasing the filtration area $[25,26]$. If renal hypoperfusion persists, it can lead to ischemic injury of renal tissue. On the other hand, elevation of the intraglomerular pressure for a long time may induce an increase of proteinuria and glomerulosclerosis in patients who have already suffered glomerular damage. Furthermore, the expression of proinflammatory cytokines such as TNF- $\alpha$, IL- $1 \beta$ or IL- 6 , and inhibitors of nitric oxide such as asymmetric dimethylarginine (ADMA), is increased in heart failure, which also contributes to progressive renal damage [27]. Our data demonstrate clearly that in addition to acute declines in the renal function in the setting of decompensated heart failure as documented in the literature, heart failure is associated with clinically significant loss of kidney function. The finding that selfreported failure is a robust predictor of subsequent decline in renal function is an important contribution of this study. It is possible that patients with heart failure have higher rates of hospitalization with repeated 'acute on chronic' declines in kidney function that eventually result in higher rates of significant declines in eGFR and subsequent ESRD $[28,29]$. These episodes may result in substantial changes in GFR in some individuals, and therefore may also contribute to why an association was seen in our study between heart failure and the occurrence of $50 \%$ decline in GFR or ESRD, and not with the rate of decline in GFR in the overall study population. However, this apparent discrepancy between the association of heart failure with 'hard outcomes' and the rate of change of GFR needs to be further explored in future studies.

The association between self-reported MI/revascularization and the development of the renal outcome had borderline statistical significance in our main analyses. We conducted sensitivity analyses considering death a competing risk rather a censoring event in the Cox regression analyses. None of the self-reported CVD variables were independently associated with the renal outcome in the competing risk analyses. Recent papers suggest caution in interpreting etiologic associations using competing risk analyses; [13] therefore, we consider these hypotheses as ones generating secondary analyses. The complex interactions between incident cardiovascular events, death and renal outcomes remain an important area for future investigation. 
Our study has a number of strengths including a diverse and well-characterized cohort of patients followed long-term with minimal loss to follow up. We collected a wide range of information to permit adjustment for important covariates. The prospective study design allows for the assessment of the time course of loss of kidney function associated with self-reported CVD. The relatively large sample size permitted subgroup analyses based on age, gender, and diabetes. However, our findings should be considered within the context of several limitations. First, ascertainment of cardiovascular disease was based on self-report. Previous studies assessing the accuracy of self-report of cardiovascular disease have shown greater accuracy for MI and stroke [30] than for heart failure [31]. However, the presence of elevated BNP and pro-BNP levels in the CRIC study participants who reported heart failure adds evidence to support the diagnosis of heart failure. While echocardiographic data is available in CRIC, it was obtained at year 1 visit of the study, and not at study entry, which is the focus of this manuscript. Based on our current findings, future papers may examine the patterns of heart failure (systolic or preserved ejection fraction) that are associated with a higher risk, and the mechanisms that mediate this risk. Self-report is easily ascertained at the bedside; given the robust predictive value in our cohort, future research may focus on validating a self-reported diagnosis of heart failure in CKD patients. Finally, since there were several comparisons, it is possible that the association may be due to chance, and these findings need to be confirmed in other cohorts.
In summary, we showed a substantial burden of prevalent CVD in a cohort of patients with CKD. Participants with CVD at baseline had higher rates of CKD progression; this risk was explained by the presence of common risk factors. Self-reported history of congestive heart failure was independently associated with a higher risk of ESRD or $50 \%$ decline in eGFR.

\section{Acknowledgments}

This work was supported by cooperative agreements from $\mathrm{Na}$ tional Institute of Diabetes and Digestive and Kidney Diseases (5U01 DK060990, 5U01 DK060984, 5U01 DK06102, 5U01 DK061021, 5U01 DK061028, 5U01 DK60980, 5U01 DK060963, and 5U01 DK060902). Additional support was provided by the following institutional Clinical Translational Science Awards and other National Institutes of Health grants: Johns Hopkins University UL1 RR-025005, University of Maryland GRCR M01 RR16500, Case Western Reserve University Clinical and Translational Science Collaborative (University Hospitals of Cleveland, Cleveland Clinic Foundation, and MetroHealth) UL1 RR-024989, University of Michigan GCRC M01 RR-000042 and CTSA UL1 RR-024986, University of Illinois at Chicago, Center for Clinical and Translational Science UL1 RR029879 Tulane/LSU/Charity Hospital General Clinical Research Center RR-05096, University of Pennsylvania Clinical and Translational Science Award NIH/ NCATS UL1 TR000003, -and Kaiser Permanente NIH/NCRR UCSF-CTSI UL1 RR-024131 and 5K24 DK002651.

\section{Disclosure Statement}

None of the authors report any financial conflict with the content of this manuscript.

\section{References}

1 Sarnak MJ, Levey AS, Schoolwerth AC, Coresh J, Culleton B, Hamm LL, McCullough PA, Kasiske BL, Kelepouris E, Klag MJ, Parfrey P, Pfeffer M, Raij L, Spinosa DJ, Wilson PW: Kidney disease as a risk factor for development of cardiovascular disease: a statement from the American Heart Association Councils on Kidney in Cardiovascular Disease, High Blood Pressure Research, Clinical Cardiology, and Epidemiology and Prevention. Hypertension 2003;42:1050-1065.

-2 Hirata Y, Kiyosue A, Takahashi M, Satonaka H, Nagata D, Sata M, Suzuki E, Nagai R: Progression of renal dysfunction in patients with cardiovascular disease. Curr Cardiol Rev 2008;4:198-202.

>3 Fox CS, Larson MG, Leip EP, Culleton B, Wilson PW, Levy D: Predictors of new-onset kidney disease in a community-based population. JAMA 2004;291:844-850.
4 Klag MJ, Whelton PK, Randall BL, Neaton JD, Brancati FL, Stamler J: End-stage renal disease in African-American and white men. 16-year MRFIT findings. JAMA 1997;277:1293-1298.

5 Glassock RJ, Rule AD: The implications of anatomical and functional changes of the aging kidney: with an emphasis on the glomeruli. Kidney Int 2012;82:270-277.

6 Cole RT, Masoumi A, Triposkiadis F, Giamouzis G, Georgiopoulou V, Kalogeropoulos A, Butler J: Renal dysfunction in heart failure. Med Clin North Am 2012;96:955-974.

7 Feldman HI, Appel LJ, Chertow GM, Cifelli D, Cizman B, Daugirdas J, Fink JC, FranklinBecker ED, Go AS, Hamm LL, He J, Hostetter T, Hsu CY, Jamerson K, Joffe M, Kusek JW, Landis JR, Lash JP, Miller ER, Mohler ER III, Muntner P, Ojo AO, Rahman M, Townsend RR, Wright JT: The Chronic Renal Insufficiency Cohort (CRIC) Study: Design and
Methods. J Am Soc Nephrol 2003;14:S148S153.

$>8$ Lash JP, Go AS, Appel LJ, He J, Ojo A, Rahman M, Townsend RR, Xie D, Cifelli D, Cohan J, Fink JC, Fischer MJ, Gadegbeku C, Hamm LL, Kusek JW, Landis JR, Narva A, Robinson N, Teal V, Feldman HI: Chronic Renal Insufficiency Cohort (CRIC) Study: baseline characteristics and associations with kidney function. Clin J Am Soc Nephrol 2009;4:1302-1311.

$\checkmark 9$ Anderson AH, Yang W, Hsu CY, Joffe MM, Leonard MB, Xie D, Chen J, Greene T, Jaar BG, Kao P, Kusek JW, Landis JR, Lash JP, Townsend RR, Weir MR, Feldman HI: Estimating GFR among participants in the Chronic Renal Insufficiency Cohort (CRIC) Study. Am J Kidney Dis 2012;60:250-261.

10 Greenland S: Dose-response and trend analysis in epidemiology: alternatives to categorical analysis. Epidemiology 1995;6:356-365. 
$\$ 11$ Lin DY, Wei LJ, Ying Z: Checking the Cox model with cumulative sums of martingalebased residuals. Biometrika 1993;80:557-572.

$\$ 12$ Fine JP, Gray RJ: A proportional hazards model for the subdistribution of a competing risk. J Am Statist Assoc 1999;94:496-509.

-13 Grams ME, Coresh J, Segev DL, Kucirka LM, Tighiouart H, Sarnak MJ: Vascular disease, ESRD, and death: interpreting competing risk analyses. Clin J Am Soc Nephrol 2012;7: 1606-1614.

-14 Levin A, Djurdjev O, Barrett B, Burgess E, Carlisle E, Ethier J, Jindal K, Mendelssohn D, Tobe S, Singer J, Thompson C: Cardiovascular disease in patients with chronic kidney disease: getting to the heart of the matter. Am J Kidney Dis 2001;38:1398-1407.

${ }_{15}$ Liu JH, Lin SY, Hsu CY, Lin HH, Liang CC, Sung FC, Huang CC: The risk for chronic kidney disease in patients with heart diseases: a 7-year follow-up in a cohort study in Taiwan. BMC Nephrol 2012;13:77.

16 Shlipak MG, Katz R, Kestenbaum B, Fried LF, Siscovick D, Sarnak MJ: Clinical and subclinical cardiovascular disease and kidney function decline in the elderly. Atherosclerosis 2009;204:298-303.

-17 Elsayed EF, Tighiouart H, Griffith J, Kurth T, Levey AS, Salem D, Sarnak MJ, Weiner DE: Cardiovascular disease and subsequent kidney disease. Arch Intern Med 2007;167:1130 1136.

18 Ronco C, McCullough PA, Anker SD, Anand I, Aspromonte N, Bagshaw SM, Bellomo R, Berl T, Bobek I, Cruz DN, Daliento L, Davenport A, Haapio M, Hillege H, House A, Katz NM, Maisel A, Mankad S, Zanco P, Mebazaa A, Palazzuoli A, Ronco F, Shaw A, Sheinfeld G, Soni S, Vescovo G, Zamperetti N, Ponikowski P: Cardiorenal syndromes: an executive summary from the consensus conference of the Acute Dialysis Quality Initiative (ADQI). Contrib Nephrol 2010;165:54-67.
19 Tumlin JA, Costanzo MR, Chawla LS, Herzog CA, Kellum JA, McCullough PA, Ronco C: Cardiorenal syndrome type 4: insights on clinical presentation and pathophysiology from the eleventh consensus conference of the Acute Dialysis Quality Initiative (ADQI). Contrib Nephrol 2013;182:158-173.

20 Cruz DN, Schmidt-Ott KM, Vescovo G, House AA, Kellum JA, Ronco C, McCullough PA: Pathophysiology of cardiorenal syndrome type 2 in stable chronic heart failure: workgroup statements from the eleventh consensus conference of the Acute Dialysis Quality Initiative (ADQI). Contrib Nephrol 2013; 182:117-136.

21 Heywood JT, Fonarow GC, Costanzo MR, Mathur VS, Wigneswaran JR, Wynne J: High prevalence of renal dysfunction and its impact on outcome in 118,465 patients hospitalized with acute decompensated heart failure: a report from the ADHERE database. J Card Fail 2007;13:422-430.

22 Hebert K, Dias A, Delgado MC, Franco E, Tamariz L, Steen D, Trahan P, Major B, Arcement LM: Epidemiology and survival of the five stages of chronic kidney disease in a systolic heart failure population. Eur J Heart Fail 2010;12:861-865.

23 House AA, Anand I, Bellomo R, Cruz D, Bobek I, Anker SD, Aspromonte N, Bagshaw S, Berl T, Daliento L, Davenport A, Haapio M, Hillege H, McCullough P, Katz N, Maisel A, Mankad S, Zanco P, Mebazaa A, Palazzuoli A, Ronco F, Shaw A, Sheinfeld G, Soni S, Vescovo $\mathrm{G}$, Zamperetti N, Ponikowski P, Ronco C: Definition and classification of Cardio-Renal Syndromes: workgroup statements from the 7th ADQI Consensus Conference. Nephrol Dial Transplant 2010;25:1416-1420.

24 Damman K, Navis G, Voors AA, Asselbergs FW, Smilde TD, Cleland JG, van Veldhuisen DJ, Hillege HL: Worsening renal function and prognosis in heart failure: systematic review and meta-analysis. J Card Fail 2007;13:599608 .
25 Forman DE, Butler J, Wang Y, Abraham WT, O'Connor CM, Gottlieb SS, Loh E, Massie BM, Rich MW, Stevenson LW, Young JB, Krumholz HM: Incidence, predictors at admission, and impact of worsening renal function among patients hospitalized with heart failure. J Am Coll Cardiol 2004;43:61-67.

26 Goh CY, Vizzi G, De Cal M, Ronco C: Cardiorenal syndrome: a complex series of combined heart/kidney disorders. Contrib Nephrol 2011;174:33-45.

27 Hatamizadeh P, Fonarow GC, Budoff MJ, Darabian S, Kovesdy CP, Kalantar-Zadeh K: Cardiorenal syndrome: pathophysiology and potential targets for clinical management. Nat Rev Nephrol 2013;9:99-111.

28 Tanaka K, Ito M, Kodama M, Maruyama H, Hoyano M, Mitsuma W, Iino N, Hirono S, Okura Y, Gejyo F, Tanabe N, Aizawa Y: Longitudinal change in renal function in patients with idiopathic dilated cardiomyopathy without renal insufficiency at initial diagnosis. Circ J 2007;71:1927-1931.

29 Sud M, Tangri N, Pintilie M, Levey AS, Naimark DM: ESRD and death after heart failure in CKD. J Am Soc Nephrol 2014;pii: ASN.2014030253.

-30 Machon M, Arriola L, Larranaga N, Amiano P, Moreno-Iribas C, Agudo A, Ardanaz E, Barricarte A, Buckland G, Chirlaque MD, Gavrila D, Huerta JM, Martinez C, Molina E, Navarro C, Quiros JR, Rodriguez L, Sanchez MJ, Gonzalez CA, Dorronsoro M: Validity of self-reported prevalent cases of stroke and acute myocardial infarction in the Spanish cohort of the EPIC study. J Epidemiol Community Health 2013;67:71-75.

31 Simpson CF, Boyd CM, Carlson MC, Griswold ME, Guralnik JM, Fried LP: Agreement between self-report of disease diagnoses and medical record validation in disabled older women: factors that modify agreement. J Am Geriatr Soc 2004;52:123-127. 